\title{
Trypanosoma cruzi: a stage-specific calpain-like protein is induced after various kinds of stress
}

\author{
Viviane Giese, Bruno Dallagiovanna, Fabricio K Marchini, Daniela P Pavoni, Marco A Krieger, \\ Samuel Goldenberg/ ${ }^{+}$
}

Instituto Carlos Chagas-Fiocruz, R. Professor Algacyr Munhoz Mader 3775, 81350-010 Curitiba, PR, Brasil

Calpains are calcium-dependent cysteine proteinases found in all living organisms and are involved in diverse cellular processes. Calpain-like proteins have been reported after in silico analysis of the Tritryps genome and are believed to play important roles in cell functions of trypanosomatids. We describe the characterization of a member of this family, which is differentially expressed during the life-cycle of Trypanosoma cruzi.

Key words: calpain-like - Trypanosoma cruzi - stress - metacyclogenesis

Understanding the differentiation process of pathogenic protozoa may contribute to the identification of alternative possibilities for developing new drugs and treatment strategies for parasitic diseases. Trypanosoma cruzi is the causative agent of Chagas disease (Chagas 1909). Its life-cycle includes the transformation from non-infective and replicating epimastigotes into nondividing and infective metacyclic trypomastigotes. This process, referred to as metacyclogenesis, occurs naturally in the gut of the triatomine insect vector and can be reproducibly mimicked in vitro under chemically defined conditions (Contreras et al. 1985).

Various cell populations can be distinguished during the in vitro metacyclogenesis process: epimastigotes harvested from growing medium (LIT), epimastigotes subjected to a nutritional stress (NS) (a requirement for differentiation), differentiating epimastigotes (parasites adhered to the culture flask at various times during the process) and metacyclic trypomastigotes (Bonaldo et al. 1988). The transcriptomes of these cell populations determined by microarray analysis have been compared and various differentially expressed genes have thereby been identified. Interestingly, the gene encoding a calpain-like protein (the gene was recently named TcCALPx11) is up-regulated in epimastigotes under NS (Epistress) (Probst et al., unpublished observations).

Calpains (CA) are calcium-dependent cysteine proteinases found in all living organisms and are involved in diverse cellular processes including apoptosis, signal transduction, differentiation and cytoskeleton remodeling (Ono et al. 1998). Calpain-like proteins (CALP) are atypical CAs and are widespread in lower eukaryotes. Most are devoid of catalytic activity due to amino acid

Financial support: CNPq, PRONEX (Fundação Araucária), PAPESFIOCRUZ

+ Corresponding author: sgoldenb@fiocruz.br

Received 25 March 2008

Accepted 13 August 2008 changes within the active-site and/or the absence of EF-hand calcium-binding domains. Nevertheless, these proteins are involved in signal transduction and cell differentiation (Dear et al. 1997). Genome sequences of the Tritryps (T. cruzi, Trypanosoma brucei and Leishmania major) have recently become available: the cysteine peptidases in these species are a large family of proteases which include CALP (Ivens et al. 2005). A recent study provided a comprehensive in silico analysis of CALP in Tritryps and reported their potential role in cell functions (Ersfeld et al. 2005). Here, we describe the characterization of a member of this family, which is differentially expressed during the life-cycle of T. cruzi.

The gene encoding the T. cruzi CALP, TcCALPx11 (GeneDB ID Tc00.1047053506563.210), was identified by microarray analysis as being differentially expressed by $T$. cruzi during metacyclogenesis. Its expression during NS preceding T. cruzi metacyclogenesis was 2.53 times higher than that observed in epimastigotes (Probst et al. unpublished). This gene is a member of group 1, the group consisting of the most conserved CALP (Ersfeld et al. 2005). TcCALPx11 has 692 amino acid residues with an estimated molecular weight of $78.2 \mathrm{kDa}$, showing $60 \%$ amino acid identity with TbCALP1.2 (GeneDB ID Tb927.1.2110) of T. brucei. The active catalytic site of calpain proteases presents an amino acid triad consisting of cysteine, histidine and arginine (Sorimachi et al. 2001). In the case of TcCALPx11, the cysteine is substituted by a serine residue; indeed, amino acid changes in the active site are common in CALP. However, bioinformatics analysis of TcCALPx11 gave no indication of putative acylation motifs, as is the case in the T. brucei related CAP5.5 (Hertz-Fowler et al. 2001), but several phosphorylation sites were identified.

We used real-time PCR (qPCR) to quantify Tccalpx11 mRNA in polysomal mRNA fractions (Goldenberg et al. 1985) from epimastigotes, epimastigotes under NS and 24h-adhered (differentiating) parasites; values obtained were normalized to those for the mRNAs encoding GAPDH (Tc00.1047053503687.20), histone H2B (Tc00.1047053511635.10) and a hypothetical protein gene (Tc00.1047053510351.80). Tccalpx11 mRNA was indeed 
2.5 times more abundant on average in epimastigotes under NS than in epimastigotes growing in complete medium (Table). There were no major differences in the amounts of the total RNAs, suggesting that stage-specific expression is the result of differential mobilization of mRNAs to the polysome fraction, as described for other T. cruzi genes (Avila et al. 2003).

Antiserum against a recombinant TcCALPx11-GSTfusion protein was used to test for TcCALPx11 production. Protein extracts from $T$. cruzi at various stages of differentiation were analyzed by western blotting and a single $80 \mathrm{kDa}$ protein band was found in epimastigotes. This corresponds to the estimated molecular weight of TcCALPx11 without post-translational acylation, thereby confirming the prediction from in silico analysis. Analysis of protein extracts from parasites during metacyclogenesis showed an increase in the abundance of TcCALPx11 in parasites under NS, whereas it was not detected in metacyclic trypomastigote extracts (Fig. 1A). Furthermore, TcCALPx11 was not detected by western blotting during T. cruzi amastigogenesis (Fig. 1B), suggesting that it is epimastigote-specific. As mentioned previously CA are involved in signal transduction and cytoesqueletal remodeling; the epimastigote-specific expression could suggest a role of TcCALPx11 in the adaptation of this form to the insect vector environment.
Proteomic and microarray analysis data suggest that several of the CALP identified in kinetoplastida are differentially expressed (Minning et al. 2003, Atwood et al. 2005). For example, the CAP5.5 protein of T. brucei is differentially expressed during the cell cycle with an increase in the procyclic stage (Hertz-Fowler et al. 2001) and the META 2 protein of Leishmania amazonensis (a SKCRP type protein) is most abundant in promastigotes (Ramos et al. 2004). We analyzed protein extracts prepared from parasites after having undergone various periods of NS and found that the abundance of TcCALPx11 increased two-fold after $1 \mathrm{~h}$ of stress (Fig. 1C). This was consistent with the microarray and real-time PCR data, which showed a 2.5 -fold increase in the expression of TcCALPx11. This increased expression at the onset of the metacyclogenesis is consistent with a role in the differentiation process; alternatively, TcCALPx11 might be a stress-induced protein. We tested three types of stress (nutritional, temperature and acidic $\mathrm{pH}$ ) and found that TcCALPx11 expression increased irrespective of the type of stress applied to the parasite (Fig. 1D). Thus, it is possible that TcCALPx11 has a general role in the $T$. cruzi stress response.

To study the function of TcCALPx11, the full-length gene was inserted into the pTEX expression vector and vector was introduced into the parasite. Western blot anal-

\section{TABLE}

Relative quantification of calpain mRNA in epimastigotes, epimastigotes under nutritional stress and adhered-epimastigotes through real time PCR (qPCR), hybridization on microarrays and Western Blot

\begin{tabular}{lccc}
\hline & Epimastigotes $^{a}$ & Epimastigotes under nutritional stress & Adhered-epimastigotes \\
\hline qPCR & & & \\
GAPDH3 & 1 & 1.96 & 0.33 \\
H2B & 1 & 2.18 & 0.28 \\
Hypothetical & 1 & 3.20 & 0.35 \\
Mean $^{b}$ & 1 & 2.50 & 0.32 \\
Microarray data $_{\text {Western Blot quantification }}$ & 1 & 2.53 & - \\
\hline
\end{tabular}

$a$ : gene expression quantification relative to epimastigotes; $b$ : using the mean of expression of the three genes (GAPDH, H2B and hypothetical protein gene) to normalize the samples. Differential expression of TcCALPx11 during metacyclogenesis. Epimastigote forms of the T. cruzi isolate $\mathrm{Dm} 28 \mathrm{c}$ were grown at $28^{\circ} \mathrm{C}$ in liver infusion tryptose (LIT) medium. Cells were differentiated in vitro into metacyclic trypomastigotes under chemically defined conditions (TAU3AAG medium) as previously described (Bonaldo et al. 1988). The parasite's polysomal RNA fraction was prepared as described by Goldenberg et al. (1985). Two-step real-time RT-PCR assays were performed in an ABI PRISM 7000 Sequence Detection System (Applied Biosystems) and results were normalized by the standard curve method using GAPDH (GAPDHf GTGATGGGGAGGCGCAAAAACTAC GAPDHr GCAAAAGCACCACTAATGACAGAA), histone H2B (H2Bf CGGTGGTGCGCGTCAACAAGAAGC H2Br CCAGGTCCGCCGGCAGCACGAG) and a hypothetic protein gene (Hypf - TGACGGGGACGAATGCCTTTTTGT Hypr - CCTCCTCCATGGCGTTGTTCTTCA) as normalizers. Samples were assayed in a $20 \mu \mathrm{L}$ reaction mixture containing 10 ng of retrotranscribed RNA from the sample and the recommended concentration of SYBR Green Master Mix (Applied Biosystems). All reactions contained 4 pmol of the specific primers (3451f - 5' CGTGCCATGAGCATGTATCC3' and 3451r - 5'GAAACGCAACTCGCACCTG3'). PCR conditions were as follows: $10 \mathrm{~min}$ at $95^{\circ} \mathrm{C}$, followed by 50 cycles of $95^{\circ} \mathrm{C}$ for $15 \mathrm{~s}$ and $55^{\circ} \mathrm{C}$ for $20 \mathrm{~s}$ and $72^{\circ} \mathrm{C}$ for $1 \mathrm{~min}$. For the SYBR Green-based assay, a melting curve analysis was performed following the amplification, to ensure that the correct product had been obtained by checking its specific melting temperature. Microarray analyses were performed using the polysomal RNA fraction of the different parasite forms. A T. cruzi PCR product microarray was analyzed by competitive hybridization in a GeneTac automated hybridization station (Genomic Solutions). Slides were scanned in a 428 Array Scanner (Affymetrix). Images were analyzed with Spot software. The resulting data were corrected for background and normalized, using the normexp and PrintTip-Loess methods, respectively, within the Limma package. Western blots were quantified using the One DScan E X 3.1 software (Scanalytic) using the expression of the PEPCK protein as a reference. All protein quantifications were performed in at least three independent assays. 

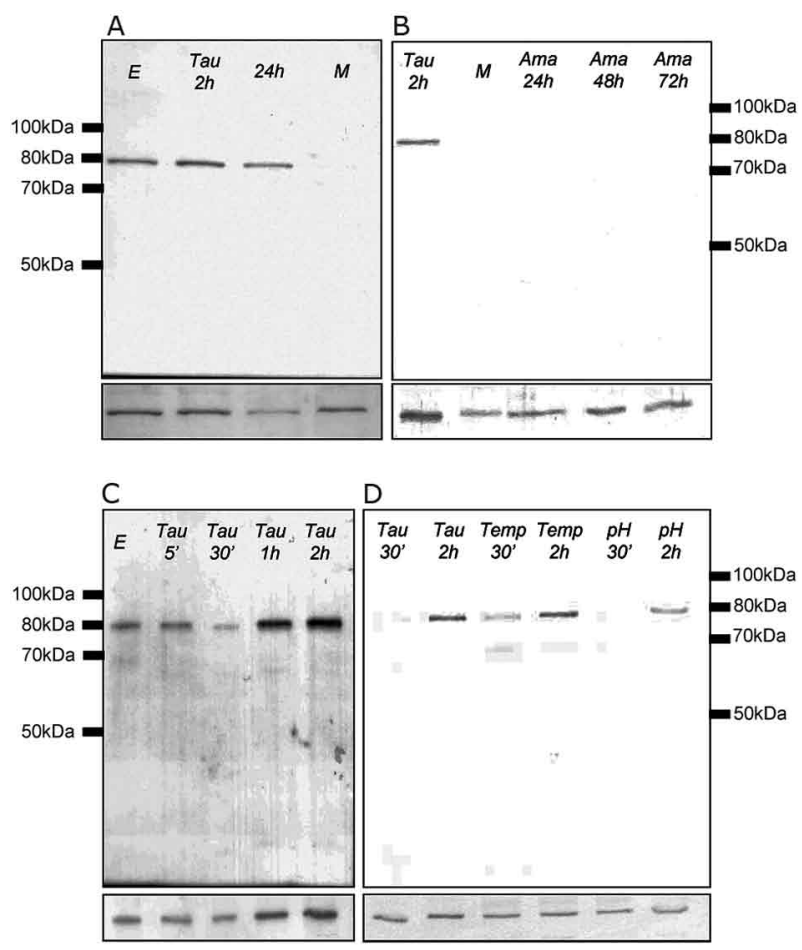

Fig. 1: western blot analysis of TcCALPx11 expression during T. cruzi metacyclogenesis (A) and amastigogenesis (B). The cells (10 7 parasites) analyzed were epimastigotes (E), epimastigotes subjected to nutricional stress by incubation in TAU medium (Contreras et al. 1985) (Tau $2 \mathrm{~h}$ ), differentiating epimastigotes ( $24 \mathrm{~h}$ ), metacyclic trypomastigotes (M) and amastigotes after various times of differentiation (Ama 24 h, 48 h, 72 h). Protein extracts from parasites after various times of nutricional stress $(\mathrm{C})$. Parasites were exposed to nutritional (Tau), temperature $\left(37^{\circ} \mathrm{C} \mathrm{Temp}\right)$ and $\mathrm{pH} 5(\mathrm{pH})$ stress for $30 \mathrm{~min}$ or 2 $h$ (D). Lower panels: same membranes were incubated with an antiPEPCK serum as a control for protein loading. To obtain the recombinant protein, the Tccalpx11 gene coding sequence was amplified by PCR (CalpF - 5' CGGGATCCTATGGCGTCATACGGG3' and CalpR - 5' CGAAGCTTCTATTCAACTTGAATG3') and inserted into the pGEX-A vector (Amersham Biosciences). The recombinant GST fusion protein partitioned mainly in the soluble fraction after induction of the E. coli M15 culture with $1 \mathrm{mM}$ IPTG. The protein samples were then purified by affinity chromatography on a gluthationeSepharose 4B columm (Amersham Pharmacia Biotech) according to the manufacturer's instructions. Swiss-Rockefeller mice were immunized weekly using intramuscular injections of approximately $10 \mu \mathrm{g}$ of purified protein. On day $24,5 \times 10^{6} \mathrm{TG} 180$ sarcoma cells were also injected into the mice to increase the quantity of serum. Total protein extracts were prepared by resuspending PBS-washed parasites in SDS-PAGE sample buffer $\left(10^{6}\right.$ parasites $\left./ \mu \mathrm{L}\right)$. Proteins were fractionated in 10\% SDS-polyacrylamide gels, transferred onto nitrocellulose membranes (Amersham) and incubated in the presence of anti serum (1/500 dilution). Membranes were thoroughly washed and incubated with alkaline phosphatase conjugated anti-mouse IgG (Sigma) to detect bound antibodies.

ysis showed a 3-fold increase of the protein in transfected parasites compared with control parasites (Fig. 2A). However, no morphological or structural alterations were evident in the transfected cells. In addition, over-production of TcCALPx11 did not alter the growth curves or the differentiation rates of the parasites (not shown).
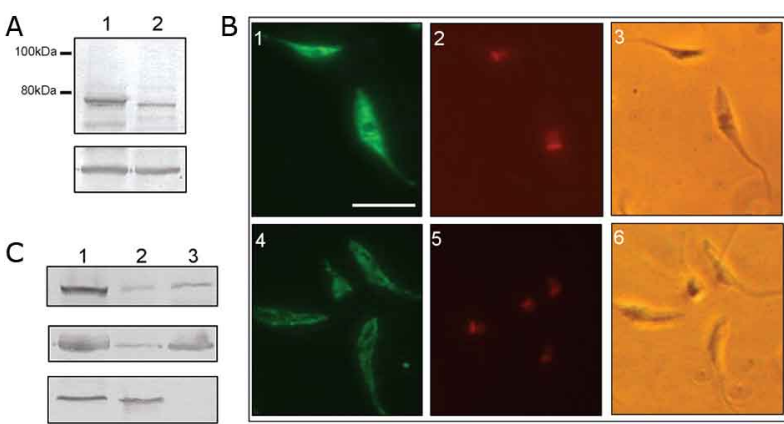

Fig. 2A: western blot analysis of protein extracts from transfected parasites (1) and control parasites (vector alone) (2). Lower panel: the same membranes are incubated with an anti-PEPCK serum as a control for protein loading. Log-phase epimastigotes were electroporated in the presence of $100 \mu \mathrm{g}$ of vector DNA as described (Lu \& Buck 1991). Transfected parasites were selected by continuous growth in the presence of $500 \mu \mathrm{g} / \mathrm{mL}$ of G418 (Sigma) and were cloned by serial dilution; B: immunofluorescence assays (IFA) of transfected epimastigotes (1) or wild-type epimastigotes (4) with propidium iodide staining $(2,5)$ and phase contrast $(3,6)$. Bar $=10 \mu \mathrm{m}$ (panel B-1). IFA were performed as previously described (Nardelli et al. 2007); C: western blot analysis of total (1), soluble (2) and insoluble (3) epimastigote protein fractions following detergent extraction, corresponding to $10^{7}$ parasites, using anti TcCALPx11 (upper panel), anti $\beta$-tubulin (middle) and anti-TcPUF6 (lower) sera.

In the various organisms in which they have been identified, CA are cytoplasmic proteins commonly associated with the cytoskeleton or cellular membranes through fatty acid modifications (Sorimachi et al. 2001). No potential sites for myristoylation or palmitoylation were found in the aminoacid sequence. The predicted absence of acyl modifications suggests that TcCALPx11 is not associated with membranes. Immunolocalization assays (Fig. 2B) with wild-type and transfected epimastigote forms indicated that TcCALPx11 is in the cytoplasm and is slightly more expressed in transfected parasites (Fig. 2B-1) than in wild-type parasites (Fig. 2B-4). T. brucei CAP5.5 calpain protein was found to be associated with the parasite cytoskeleton. We performed biochemical fractionation of cells into detergent soluble and insoluble fractions as previously described (Woods et al. 1989). Western blot analysis of the corresponding protein fractions showed that the protein partitioned mainly in the insoluble fraction, though some signal could be observed in the soluble fraction. Expressions of $\beta$-tubulin and TcPUF6, a soluble cytoplasmic RNA binding protein (Dallagiovanna et al. 2005), were used as controls of the integrity of protein extracts (Fig. 2C).

We also tried to characterize any protease activity of TcCALPx11: we used SDS polyacrylamide gels containing co-polymerized gelatin and in vitro protease assays (d'Avila-Levy et al. 2003) to assay the soluble recombinant fusion protein and the native protein immunoprecipitated from T. cruzi extracts. However, we detected no proteolytic activity, consistent with other CLP. The loss of the protease function and the differential expression observed suggests that this protein may have a role in signal transduction. 


\section{REFERENCES}

Atwood JA, Weatherly DB, Minning TA, Bundy B, Cavola C, Opperdoes FR, Orlando R, Tarleton RL 2005. The Trypanosoma cruzi proteome. Science 309: 473-476.

Ávila AR, Dallagiovanna B, Yamada-Ogatta SF, Monteiro-Goes V, Fragoso SP, Krieger MA, Goldenberg S 2003. Stage-specific gene expression during Trypanosoma cruzi metacyclogenesis. Genet Mol Res 21: 159-168.

Bonaldo MC, Souto-Padron T, Souza W, Goldenberg S 1988. Cellsubstrate adhesion during Trypanosoma cruzi differentiation. $J$ Cell Biol 106: 1349-1358.

Chagas C 1909. Nova tripanozomiaze humana. Estudos sobre a morfolojia e o ciclo evolutivo do Schizotrypznum cruzi n. gen, n. sp., Ajente etiolojico de nova entidade mórbida do homem. Mem Inst Oswaldo Cruz 1: 159-218.

Contreras VT, Salles JM, Thomas N, Morel CM, Goldenberg S 1985. In vitro differentiation of Trypanosoma cruzi under chemically defined conditions. Mol Biochem Parasitol 16: 315-327.

Dallagiovanna B, Diaz LP, Sotelo-Silveira J, Smircich P, Duhagon MA, Garat B 2005. Trypanosoma cruzi: molecular characterization of TcPUF6, a Pumilio protein. Exp Parasitol 109: 260-264.

d'Avila-Levy CM, Souza RF, Gomes RC, Vermelho AB, Branquinha MH 2003. A novel extracellular calcium-dependent cysteine proteinase from Crithidia deanei. Arch Biochem Biophys 420: 1-8.

Dear N, Matena K, Vingron M, Bohem T 1997. A new subfamily of vertebrate calpains lacking a calmodulin-like domain: implications for calpain regulation and evolution. Genomics 45: 175-184.

Ersfeld K, Barraclough H, Gull K 2005. Evolutionary relationship and protein domain architecture in an expanded calpain superfamily in kinetoplastid parasites. J Mol Evol 61: 742-757.

Goldenberg S, Salles JM, Contreras VT, Lima Franco MP, Katzin AM, Colli W, Morel CM 1985. Characterization of messenger RNA from epimastigotes and metacyclic trypomastigotes of Trypanosoma cruzi. FEBS Lett 180: 265-270.

Hertz-Fowler C, Ersfeld K, Gull K 2001. CAP5.5, a life-cycle-regulated, cytoskeleton-associated protein is a member of a novel family of C-related proteins in Trypanosoma brucei. Mol Biochem Parasitol 116: 25-34.
Ivens AC, Peacock CS, Worthey EA, Murphy L, Aggarwal G, Berriman M, Sisk E, Rajandream MA, Adlem E, Aert R, Anupama A, Apostolou Z, Attipoe P, Bason N, Bauser C, Beck A, Beverley SM, Bianchettin G, Borzym K, Bothe G, Bruschi CV, Collins M, Cadag E, Ciarloni L, Clayton C, Coulson RM, Cronin A, Cruz AK, Davies RM, De Gaudenzi J, Dobson DE, Duesterhoeft A, Fazelina G, Fosker N, Frasch AC, Fraser A, Fuchs M, Gabel C, Goble A, Goffeau A, Harris D, Hertz-Fowler C, Hilbert H, Horn D, Huang Y, Klages S, Knights A, Kube M, Larke N, Litvin L, Lord A, Louie T, Marra M, Masuy D, Matthews K, Michaeli S, Mottram JC, Muller-Auer S, Munden H, Nelson S, Norbertczak H, Oliver K, O'neil S, Pentony M, Pohl TM, Price C, Purnelle B, Quail MA, Rabbinowitsch E, Reinhardt R, Rieger M, Rinta J, Robben J, Robertson L, Ruiz JC, Rutter S, Saunders D, Schafer M, Schein J, Schwartz DC, Seeger K, Seyler A, Sharp S, Shin H, Sivam D, Squares R, Squares S, Tosato V, Vogt C, Volckaert G, Wambutt R, Warren T, Wedler H, Woodward J, Zhou S, Zimmermann W, Smith DF, Blackwell JM, Stuart KD, Barrell B, Myler PJ 2005. The genome of the kinetoplastid parasite, Leishmania major. Science 309: 436-442.

Lu HY, Buck GA 1991. Expression of a gene in Trypanosoma cruzi epimastigotes. Mol Biochem Parasitol 44: 109-114.

Minning TA, Bua J, Garcia GA, McGraw RA, Tarleton RL 2003. Microarray profiling of gene expression during trypomastigote to amastigote transition in Trypanosoma cruzi. Mol Biochem Parasitol 131: 55-64.

Nardelli S, Ávila AR, Freund A, Motta MC, Manhaes L, de Jesus TCL, Schenkman S, Fragoso SP, Krieger MA, Goldenberg S, Dallagiovanna B 2007. Small-subunite rRNA processome proteins are translationally regulated during differentiation of Trypanosoma cruzi. Eukaryotic cell 6: 337-345.

Ono Y, Sorimachi H, Suzuki K 1998. Structure and Physiology of Calpain, an enigmatic protease. Biochem Biophys Res Commun 245: 289-294.

Ramos CS, Franco FAL, Smith DF, Uliana SR 2004. Characterization of a new Leishmania META gene and genomic analysis of the META cluster. FEMS Microbiol Lett 238: 213-219.

Sorimachi H, Suzuki K 2001. The structure of calpain. J Biochem 129: 653-664.

Woods A, Baines AJ, Gull K 1989. Evidence for a Mr 88000 glycoprotein with a transmembrane association to a unique flagellum attachment region in Trypanosoma brucei. J Cell Sci 93: 501-508. 